\title{
Effects of subthalamic lesions on active avoidance performance
}

\author{
W. GARY THOMPSON and LESLIE H. HICKS \\ Howard University, Washington, D.C. 20059
}

Thirty albino rats were tested on acquisition and retention of a two-way active avoidance task with a brief $(2.5-\mathrm{sec})$ warning signal duration. Animals were assigned to three groups: (1) subthalamic lesions, (2) sham-operated controls, and (3) unoperated controls that received subthalamic lesions after acquisition but before retention testing. Subthalamic lesions impaired both acquisition and retention performance.

Hicks and Birren (1970) proposed that the basal ganglia are importantly involved in psychomotor slowing. The subthalamic nucleus has major afferent and efferent connections with the globus pallidus (Carpenter \& Strominger, 1967; Knook, 1965; Nakamura \& Sutin, 1972), the main efferent nucleus of the basal ganglia. Lesions of the pallidum impair sensorimotor (Levine \& Schwartzbaum, 1973) and avoidance performance (Beatty \& Siders, 1977), while lesions of the subthalamic nucleus itself in cats led to a lack of attention and responsiveness to sensory stimuli (Adey \& Lindsley, 1959; Adey, Walter, \& Lindsley, 1962; Lindsley, Barton, \& Atkins, 1970). Thompson (1974) reported that rats with bilateral subthalamic lesions fail to relearn a threecul maze under shock avoidance motivation. Thompson (1978) also reported that subthalamic rats showed retention deficits on an active avoidance habit.

\section{METHOD}

Thirty male albino Sprague-Dawley (Madison, Wisconsin) rats were used. They weighed between 300 and $325 \mathrm{~g}$ at the start of the experiment. Fifteen rats were randomly assigned to the subthalamic group. Seven of the rats were assigned to a sham-operated group, and eight to an unoperated group. Lesions were made by passing a $1-\mathrm{mA}$ anodal current for $7 \mathrm{sec}$ through a stainless steel electrode insulated with Diamel, except for $.5 \mathrm{~mm}$ exposed at the tip. The stereotaxic coordinates with respect to bregma were: $-1.4 \mathrm{~mm}$ posterior, $2.5 \mathrm{~mm}$ lateral, and $8.1 \mathrm{~mm}$ below the surface of the skull.

Testing on the acquisition phase of the avoidance task began 15-20 days after surgery. The testing was done in a Lehigh Valley Electronics two-compartment, toggle-floor shuttlebox (Model 146-04). Animals received 50 trials/day for 4 days on a two-way active avoidance task. The warning signal was a buzzer of $2.5 \mathrm{sec}$ duration. If the rat failed to cross a $7.62-\mathrm{cm}$-high barrier to the safe compartment during the 2.5 -sec period, footshock $(.5 \mathrm{~mA} \mathrm{ac})$ was delivered through the grid floor. Both buzzer and footshock were terminated when the animal ran to the safe compartment. The intertrial interval was $35 \mathrm{sec}$.

On the day after completion of acquisition training, all the unoperated control animals received bilateral lesions of the

This research was supported by NIH Grant 1 R01 NS 09630 to L. H. Hicks. Address reprint requests to Leslie H. Hicks, Department of Psychology, Howard University, Washington, D.C. 20059 . subthalamic nuclei. Retention testing of all animals in the experiment occurred $20-25$ days after surgery on the unoperated controls. Animals received 50 trials/day for 4 days on the retention task.

\section{RESULTS}

\section{Histology}

Although lesions mainly damaged the subthalamic nuclei, in most animals adjacent tissue was also invaded: primarily, the cerebral peduncles, internal capsule, zona incerta, and Forel Fields $\mathrm{H}_{1}$ and $\mathrm{H}_{2}$. Representative lesions can be seen in Figure 1.

\section{Avoidance}

Figure 2 shows the mean percent of avoidances during acquisition and retention testing. Mann-Whitney tests showed that the subthalamic group made significantly $(\mathrm{p}<.05)$ fewer avoidance responses $($ mean $=8.46)$ during acquisition than the unoperated group (25.88) or the sham-operated group (38.29). Although subthalamic animals did not make significantly fewer total avoidances compared to sham-operated animals during retention (Mann-Whitney $\mathrm{z}=1.79, \mathrm{p}=.08$ ), their performance on Day 4 was significantly inferior to

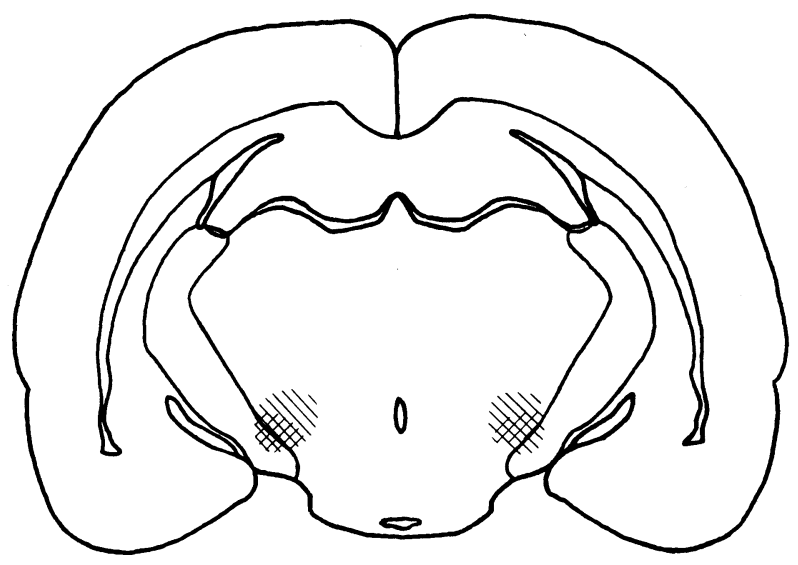

Figure 1. Representative subthalamic lesions. 


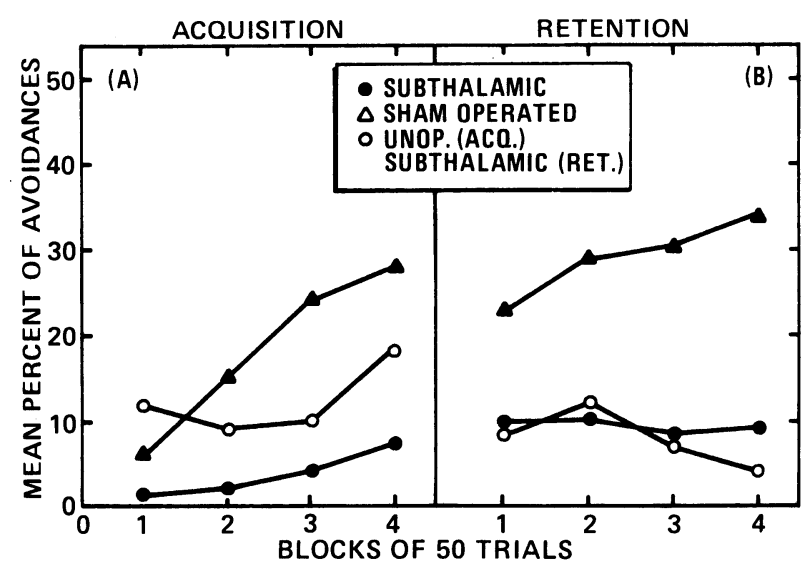

Figure 2. Mean percent of avoidance responses in acquisition and retention-testing sessions.

sham-operated Day 4 performance $(z=2.26, \mathrm{p}<.03)$. Figure 2 depicts this improving performance by shamoperated animals during retention compared to the lack of improvement in the subthalamic groups.

Table 1 shows the mean response latencies for the various groups during acquisition and retention. MannWhitney tests revealed significant differences between sham-operated and subthalamic groups during acquisition $(\mathrm{z}=2.25, \mathrm{p}=.03)$ and during retention $(\mathrm{z}=2.07$, $\mathrm{p}=.05)$.

\section{DISCUSSION}

The number of avoidance responses was not very high in any of the groups in this study. This finding has been reported before for the Sprague-Dawley strain (Nakamura \& Anderson, 1962). Yet the subthalamic animals in the present study performed worse on acquisition and retention than did controls.

Table 1

Mean Response Latency (in Seconds)

\begin{tabular}{lrcc}
\hline & N & $\begin{array}{c}\text { Acquisi- } \\
\text { tion }\end{array}$ & $\begin{array}{c}\text { Reten- } \\
\text { tion }\end{array}$ \\
\hline Subthalamic (Acquisition) & 15 & 2.46 & 2.44 \\
Sham-Operated & 7 & 2.22 & 2.19 \\
Unoperated Control & 8 & 2.37 & 2.47 \\
\hline
\end{tabular}

Note-There were 400 acquisition trials and 400 retention trials. Unoperated controls were given bilateral subthalamic operations and then tested for retention.
Our subthalamic rats did not'show any obvious motor or postural defects analogous to the hypokinesis reported in subthalamic cats by Lindsley et al. (1975), although our subthalamic rats did show behavior similar to the lack of awareness of environmental stimuli reported by those authors. The results of this study show that, among bilaterally lesioned structures of the male rat basal ganglia, the subthalamic nuclei produce greater deficits than those found in caudate animals, and deficits similar to those of globus pallidus and substantia nigra animals (Hicks, in press).

\section{REFERENCES}

Adey, W. R., \& Lindsley, D. F. On the role of subthalamic areas in the maintenance of brain-stem reticular excitability. Experimental Neurology, 1959, 1, 407-426.

Adey, W. R., Walte R, D. O., \& Lindsley, D. F. Subthalamic lesions. Archives of Neurology, 1962, 6, 194-207.

Be atty, W. W., \& Siders, W. A. Effects of small lesions in the globus pallidus on open-field and avoidance behavior in male and female rats. Bulletin of the Psychonomic Society, 1977, 10, 98-100.

Carpenter, M. B., \& Strominger, N. L. Efferent fibers of the subthalamic nucleus in the monkey. A comparison of the efferent projections of the subthalamic, substantia nigra, and globus pallidus. American Journal of Anatomy, 1967, 121, 41-72.

Hicks, L. H. The basal ganglia and psychomotor behavior. In R. F. Thompson, L. H. Hicks, \& A. V. Schvirkov (Eds.), Neuronal and neurophysiological mechanisms of goal directed behavior. New York: Academic Press, in press.

Hicks, L. H., \& Birren, J. E. Aging, brain damage, and psychomotor slowing. Psychological Bulletin, 1970, 74, 377-396.

KNooK, H. L. The fibre-connections of the forebrain. Assen, The Netherlands: Van Gorcum, 1965.

Levine, M. S., \& Schwartzbaum, J. S. Sensorimotor functions of the striatopallidal system and lateral hypothalamus and consummatory behavior in rats. Journal of Comparative and Physiological Psychology, 1973, 85, 615-635.

Lindsley, D. F., Barton, R. J., \& Atrins, R. J. Effects of subthalamic lesions on peripheral and central arousal thresholds in cats. Experimental Neurology, 1970, 26, 109-119.

Nakamura, C. Y., \& Anderson, N. H. Avoidance behavior differences within and between strains of rats. Journal of Comparative and Physiological Psychology, 1962, 55, 740-747.

Nakamura, S., \& Sutin, J. The pattern of termination of pallidal axons upon cells of the subthalamic nucleus. Experimental Neurology, 1972, 35, 254-264.

Thompson, R. Localization of the "maze memory system" in the white rat. Physiological Psychology, 1974, 2, 1-29.

Thompson, R. A behavioral atlas of the rat brain. New York: Oxford University Press, 1978.

(Received for publication July 10, 1979.) 